\title{
A resiliência infantil no divórcio dos pais sob o olhar de professores do ensino fundamental
}

\author{
The resilience of children in parents divorce under the look of teachers \\ of basic education
}

http://dx.doi.org/10.5007/2178-4582.2014v48n1p20

\section{Camila Comin Pizzolo Gaidzinski, Denise Nuernberg, Patrícia Maria Spido \\ e Rosa Nadir Teixeira Jerônimo \\ Universidade do Extremo Sul Catarinense, Criciúma/SC, Brasil}

\begin{abstract}
A presente pesquisa trata da resiliência infantil no divórcio dos pais, sob o olhar de professores do ensino fundamental. O objetivo do trabalho foi investigar o comportamento infantil, na percepção de professores de $1^{\mathrm{a}}$ a $6^{\mathrm{a}}$ séries, para com o divórcio dos pais, observando as estratégias desenvolvidas pela criança para o enfrentamento desta situação, uma vez que a dissolução familiar pode se tornar dolorosa e ocasionar desajustes emocionais nos filhos. Trata-se de uma pesquisa de campo, de natureza qualitativa, do tipo exploratória, instrumentalizada por meio de uma entrevista semiestruturada, desenvolvida com o quadro de docentes do ensino fundamental de um colégio da região sul do estado de Santa Catarina. Os dados obtidos revelam diferentes movimentações do comportamento da criança frente ao divórcio, enfatizando-se que a resiliência infantil no contexto desta pesquisa está diretamente associada com as ações parentais.
\end{abstract}

Palavras-chave: Resiliência - Crianças - Divórcio - Professores
This research deals with the resilience of children front of their parents divorce, in the view of elementary school teachers. This study aims to investigate the children's behavior, through the perception of teachers of 1st to 6th grade, toward their parents' divorce, noting the strategies developed by the child to face this situation, since family dissolution can become painful and cause emotional maladjustment to children. This is an exploratory and qualitative field research carried out through a semistructured interview developed with the teaching staff of a primary school located in the southern state of Santa Catarina. Data showed different movements in children behavior in relation to divorce, emphasizing that children's resilience, in the context of this research, is directly associated with parental actions.

Keywords: Resilience - Children - Divorce - Teachers

\section{Introdução}

A relação matrimonial entre homem e mulher tem sido, ao longo da história humana, uma das relações primordiais, já que, por meio dela, há continuidade e sustentação da existência humana. Entretanto, verifica-se que essa relação está estruturada de acordo com fatores culturais, sociais e políticos da comunidade em que está inserida. No decorrer da história da humanidade, a família vem passando por modificações que acompanham o modo de pensar e de agir do homem na sociedade, refletindo-se em sua realidade. Nesse contexto, o cenário brasileiro e mundial, acerca das relações e estruturas familiares, vem se adequando à realidade social e cultural da atualidade, culminando num notável índice de divórcios . 
De acordo com dados do IBGE - Instituto Brasileiro de Geografia e Estatística, o índice de divórcios atingiu seu ápice no ano de 2010, quando houve, "desde o início da série histórica das estatísticas do registro civil, em 1984, um acréscimo de 36,8\% no número de divórcios em relação à 2009" (BRASIL, 2010). Este fenômeno já foi raro, ou quase inexistente nas décadas e nas gerações anteriores; mas, passível às transformações sociais, o divórcio tornou-se fato presente e constante na sociedade.

As causas para elevado índice podem incluir, conforme Peck e Manocherian (2001), fatores associados à instabilidade conjugal, como o aspecto financeiro, o aspecto cultural, a idade, entre outros aspectos, vistos melhor a seguir. Destaca-se a revolução feminista, e a luta das mulheres pela conquista de espaços, em igualdade com os homens, e a reivindicação de direitos que repercutiram nas relações conjugais, como direitos sociais, culturais e econômicos.

O divórcio mostra-se como um acontecimento social, no qual familiares, cônjuges, filhos e demais envolvidos necessitam adaptar-se à nova situação e a todas às alterações que ela proporciona. De modo que, os filhos são, em sua maioria, diretamente afetados pela dissolução familiar (ASSIS, 2006), como enfatiza esta pesquisa. Para a criança, o divórcio dos pais pode significar uma ruptura que deixará marcas por toda a vida, pois trará o medo acerca do futuro, culpa pela separação dos pais, ansiedade, insegurança, mágoa e raiva de seus genitores (PAPALIA; OLDS; FELDMAN, 2006).

Diante disso, esta pesquisa limita-se ao ambiente escolar, um dos ricos universos infantis e relevante lócus de investigação do comportamento da criança, bem como de sua resiliência. Neste caso, são os professores, os profissionais da educação aqui escolhidos, convidados a revelarem suas percepções sobre as reações dos pequenos ao divórcio dos pais, quanto à presença de uma capacidade adaptativa, de uma "reestruturação e crescimento em resposta à crise e ao desafio" (WALSH, 2005, p. 4) de como o divórcio pode ser vivenciado pela criança.

\section{Resiliência}

O termo resiliência se origina do latim resilio, não havendo ainda uma única definição para tal. Trazido pelas ciências exatas, como a Física, a palavra resiliência é traduzida como a capacidade elástica de alguns materiais, após sofrerem tensões e deformações, de retornarem ao seu estado anterior, voltar à sua essência, à sua origem, devido à flexibilidade à determinada pressão (OLIVEIRA et al., 2008).

Importada para as ciências humanas, tem-se a resiliência como um conceito relativamente novo para o campo da Psicologia. Nela, "a relação tensão/pressão com deformação não-permanente do material, corresponderia à relação situação de risco/estresse/experiências adversas com respostas finais 
de adaptação/ajustamento no indivíduo" (YUNES, 2001, p. 18). Refere-se, assim, à capacidade que um indivíduo tem de agir pró-ativamente aos eventos estressores, à capacidade de superação das crises e das adversidades eventuais da vida, como por exemplo, a morte de um ente querido, a perda de emprego, estar acometido por uma enfermidade e o próprio divórcio. Conforme Grunspun (2006, p. 4), "resiliência é o indivíduo que, submetido a traumas, estresses ou catástrofes, se recupera psicologicamente e não se torna vítima, por apresentar resiliência".

A situação adversa, ou o ocasional conflito, não é negada; em contrapartida, ele passa a ser vivenciado, na perspectiva resiliente, de forma que haja movimentos na busca por meios e estratégias para melhor solucioná-lo. Ademais, Junqueira e Deslandes (2003, p. 229) consideram resiliência como a "possibilidade de construção de novos caminhos de vida e de um processo de subjetivação, a partir do enfrentamento de situações estressantes e/ou traumáticas", propondo, assim, aprendizado mediante à situação-problema.

Entretanto, nem todas as pessoas são resilientes ou obtêm essa capacidade de superação. A resiliência está associada ao contexto social no qual um indivíduo foi ou se encontra inserido, às suas crenças, ao seu sistema familiar, aos seus traços de personalidade, às suas experiências de vida, bem como, à sua exposição aos eventos estressores. O indivíduo observa, interpreta e lida com um fenômeno de acordo com a visão que tem de si mesmo, de homem e de mundo, a partir de sua realidade. Tanto que, o evento pode ser o mesmo, mas é experienciado de diferentes maneiras (YUNES, 2003).

Os programas de promoção podem ser caminhos eficazes para o desenvolvimento da resiliência, seja em crianças, em adolescentes, em adultos ou em idosos (JUNQUEIRA; DESLANDES, 2003); e, permitem que os fatores de proteção, potencialmente, se sobressaiam aos fatores de risco que permeiam características e condições pessoais de possível prejuízo para o indivíduo, haja vista que os fatores de proteção neutralizam as respostas negativas que os fatores de risco provavelmente dariam (WALSH, 2005).

A escola tem possibilidade de atuar na promoção de resiliência. Além de ser um espaço de desenvolvimento cognitivo, voltado para a aprendizagem, um desenvolvimento emocional concomitantemente acontece. De acordo com Grunspun, "[...] a escola também pode servir como escudo protetor para ajudar crianças a resistirem às múltiplas vicissitudes que podem passar no mundo estressante" (2006, p. 17). Uma abordagem para com os valores, sentimentos e vivências infantis, exploradas dentro de uma educação emocional, torna-se oportuna a esta proposta.

\section{O Divórcio dos Pais}

A família é a instituição mais antiga e preciosa da história humana. Como aborda Brandão (2008), é vista como núcleo fundamental da sociedade, le- 
galizada através da ação do Estado, composta por pai, mãe e filhos (família nuclear), ou por outros membros ligados por laços consanguíneos ou de dependência (família extensa). Ela tem como função garantir e promover o desenvolvimento dos seus membros mediante uma saúde física e mental, produzindo pais e filhos autônomos e saudáveis.

Com sua formação, naturalmente houve o nascimento de papéis sociais, como o papel de pai, de mãe e dos filhos. Atrelados a estes, o nascimento de funções e de atribuições dentro das famílias também ocorreu, gerando seu estilo próprio, seus ciclos e sua dinâmica (BRANDÃO, 2008). Os papéis consolidaram-se em conjunto com a herança histórico-cultural de cada nação e não são estáticos, se modificam, à medida que a sociedade, em constante movimento, reconstrói novos parâmetros e ideais de vida.

O homem, o pai, o patriarca da família, ganhou direitos, como o de ser chefe e detentor da autoridade de sua prole, e deveres, como o de garantir a provisão necessária para uma vida suprida, tratando-se de questões materiais, de higiene e de saúde. Já as mulheres, segundo Carter e McGoldrick (2001, p. 14): "suas identidades eram determinadas primariamente por suas funções familiares como mãe e esposa", papel este que sofreu transformações socioculturais, fazendo desta mãe e esposa uma trabalhadora independente.

A entrada da mulher no mercado de trabalho, o número ascendente de divórcios, recasamentos, as uniões homoafetivas e outras transformações no campo social, marcaram profundas mudanças de papéis (MCGOLDRICK, 2001; BRANDÃO; 2008). Por consequência, há o surgimento de novas estruturas e de novos arranjos familiares, deixando cada vez mais de lado, o modelo tradicional na definição de família. Para Brandão, "o conceito de família amplia-se, na medida em que passa a legitimar a diversidade de uniões existentes no contexto brasileiro" (2008, p. 63).

Um dos cenários existentes, em meio a todas essas modificações é o divórcio dos pais. "O divórcio trouxe um leque de novas configurações e organizações familiares" (HACK; RAMIRES, 2010, p. 87). Ele acontece em resposta à insatisfação conjugal e é caracterizado, na maioria das vezes, por um período de crise, um momento estressante, conflituoso e perturbador para toda a família, o qual é sentido e interpretado por diferentes maneiras por seus membros. Segundo Peck e Manocherian (2001), há importantes fatores etiológicos associados à instabilidade conjugal, tais como: a) idade e gravidez pré-conjugal: quando a noiva tem idade inferior aos 18 anos e o noivo menos de 20 anos, ainda quando a mulher se casa grávida; b) instrução: se a mulher é mais instruída e o homem menos; c) salário: se a mulher ganha mais do que seu marido, no sentido de que, assim, ela se sente mais independente e autônoma diante de suas decisões; d) emprego: quando o trabalho do marido não é estável, modificando seu salário; e) nível socioeconômico: no qual os menos favorecidos correm um maior risco pelo fato de que as questões financeiras estarão sempre sendo colocadas em discussão; f) raça: casamentos inter-raciais 
pelo preconceito ainda existente, da necessária aceitação não só do cônjuge, bem como de sua família extensa.

Contudo, não se pode afirmar que a presença destes fatores culminará num divórcio, mas, são aspectos a serem observados pois colaboram para o aumento da probabilidade de sua ocorrência. Peck e Manocherian (2001) ainda colocam que o divórcio passa por etapas que antecedem sua decisão final. A primeira delas envolve a Cognição Individual, quando um dos cônjuges já está considerando esta hipótese, pensando sobre ela e, assim, inicia um processo de separação emocional, marcado pela distância física do parceiro, pelas discussões e pelas acusações.

Num segundo momento, chamado de Metacognição Familiar, a ideia do rompimento é revelada em família, gera frustrações e um grande desajuste emocional, podendo haver negação por parte de um dos cônjuges. Vale ressaltar que a tomada de iniciativa de expor a insatisfação conjugal, na maioria das vezes, é dada pelas mulheres. A terceira etapa, por sua vez, refere-se à Separação do Sistema, a partir da qual, o rompimento acontece de fato, trazendo um novo estilo de vida.

Logo, a Reorganização do Sistema abrange as transições, as adaptações acerca das mudanças que o divórcio desencadeia. Inclui novas rotinas familiares, delimitações e remodelamento das relações sociais já formadas. Por fim, há a Redefinição do Sistema, quando as etapas anteriores já foram resolvidas e a família alcança uma nova autodefinição, um novo modelo de papéis e de regras.

Nessas etapas, a família, provavelmente encontra-se envolta em dúvidas e angústias a respeito de como será sua nova vida em face dos desdobramentos que incitam o divórcio. Questões envolvendo a disputa da guarda dos filhos, como comunicá-los sobre o divórcio, os recasamentos, os declínios econômicos, o distanciamento físico e emocional de um dos genitores, do contato com os amigos já estabelecidos pelo casal. Inevitavelmente, a família se depara com o desafio de reorganizar seu sistema familiar e de ajustar-se ao novo.

\section{A resiliência infantil no divórcio dos pais}

Em filhos adultos, adolescentes ou crianças, ainda que reajam de maneira distinta, o divórcio e todo o seu processo, na maioria das vezes, acaba por gerar um verdadeiro tumulto emocional, implicando um nível de ansiedade e de mudanças de comportamento. Principalmente, para as crianças, este cenário é visto e experienciado de forma confusa, uma vez que, não têm clareza para compreender tal fenômeno. Os filhos podem se sentir culpados e não entenderem o motivo da saída de casa ou o distanciamento de um dos pais da sua vida e do seu convívio diário (PAPALIA; OLDS; FELDMAN, 2006).

As crianças respondem de acordo com o sexo, a personalidade, a idade, a maturidade e a etapa do desenvolvimento em que se encontram. Para com 
a terceira infância, configurada pela idade de 6 aos 12 anos, o divórcio dos pais permeia sentimentos de culpa, fantasias de reconciliação, sentimentos de raiva, aparecimento de fobias, mudanças comportamentais, perda de confiança e sensação de falsa segurança, assim como dificuldades escolares, além de sintomas psicossomáticos (ÁVILA, 2004).

É necessário haver um preparo, uma conversa sobre esta decisão com os filhos, de acordo com suas idades. Conforme Ávila (2004, p. 21), "dentre as várias necessidades sentidas pela criança durante esse período de transição, encontram-se: não ser envolvida no conflito; compreender que não é responsável pela separação". Por isso, um diálogo esclarecedor acerca da real situação deve ser realizado. "Quando a comunicação é vaga, distorcida ou permanece não resolvida, ela gera confusão, mal-entendidos, pois os membros operam com suposições equivocadas [...]" (WALSH, 2005, p. 105).

Além disso, a criança precisa encontrar a liberdade para se expressar, para conversar com cada um de seus pais, tal como estar a par do que está vivenciando. Desta forma, uma melhor elaboração da situação é pretendida de maneira que ocorra uma adaptação menos confusa e conflituosa ao novo contexto. Uma boa comunicação é essencial para todas as famílias, independente do contexto, e fortalece a resiliência de seus membros. Ela facilita o funcionamento familiar e se torna um instrumento poderoso no divórcio dos pais, além de contribuir na promoção da resiliência familiar, referindo-se "aos processos de enfrentamento e adaptação na família como unidade funcional" (WALSH, 2005, p. 14).

Aspectos como clareza, expressão emocional aberta e resolução colaborativa dos problemas devem compor a comunicação da família. Eles aparecem na forma de mensagens claras, diretas e específicas entre seus integrantes, no compartilhamento e na exposição dos sentimentos e na postura pró-ativa na resolução de conflitos.

O perfil da criança resiliente conta com algumas características em especial (GRUNSPUN, 2006): a) competência social: demonstra habilidades sociais, consegue se comunicar e ter flexibilidade; b) competência para resolver problemas: procura soluções e suas alternativas, até mesmo a busca de ajuda; c) autonomia: independência e autocontrole; d) confiança no futuro: tem aspirações, é persistente, esforçada e otimista; e) e se beneficia de fatores de proteção contra fatores de risco, abrangendo toda ou quaisquer das características citadas acima.

O rompimento conjugal não deve significar também um rompimento dos vínculos afetivos entre pais e filhos, visto que a presença dos referenciais parentais colabora para o desenvolvimento saudável na vida da criança. Para Carter e McGoldrick (2001, p. 23), "as famílias em que as questões emocionais do divórcio não estão adequadamente resolvidas podem permanecer emocionalmente paralisadas por anos, se não por gerações”. Assim sendo, considerar a resiliência infantil no divórcio dos pais 
é atentar-se que, neste período, há possibilidade de um comprometimento psíquico da criança.

\section{Metodologia}

Optou-se pela realização de uma pesquisa de campo, de natureza qualitativa e do tipo exploratória, a qual proporciona e permite maiores interações com o seu tema e problema (GIL, 2002). Além do levantamento bibliográfico, uma entrevista semiestruturada oportunizou a coleta de dados, pois, como instrumento de pesquisa, a entrevista objetiva buscar informações sobre alguma realidade (APPOLINÁRIO, 2006). Conforme os princípios éticos, o projeto de pesquisa deste artigo foi aprovado pelo Comitê de Ética da Universidade do Extremo Sul Catarinense (Parecer 148.852, de 26/11/2012).

A população envolvida compõe o quadro de docentes do ensino fundamental de um colégio da Região Sul/SC, composta por 5 professoras do sexo feminino, com experiência entre 20 a 30 anos em educação. A entrevista envolveu 10 questões respondidas na forma de um diálogo, dentro dos espaços cedidos pela escola, e ocorreu com o consentimento das participantes, sendo gravada e, posteriormente, transcrita. Para a identificação de cada professora, as letras do alfabeto $\mathrm{V}, \mathrm{W}, \mathrm{X}, \mathrm{Y}$ e $\mathrm{Z}$ foram usadas, a fim de manter o sigilo das entrevistadas, correspondendo às séries infantis do $1^{\circ}$ ao $5^{\circ}$ ano.

A escolha desta população foi motivada por ser o professor uma das figuras principais na infância, tornando-se importante referencial. "[...] o professor pode ser considerado um dos melhores mediadores do desenvolvimento das crianças" (MOLON; SANTOS, 2008, p. 5). Ele contribui para a formação de competências e de habilidades de que as crianças farão uso ao longo de sua vida. Além disso, conta com a oportunidade de conviver com as crianças todos os dias da semana, obtendo uma aproximação física e afetiva, e também por ser uma figura neutra dentro da pesquisa apresentada.

Perceber se acontecem alterações dentro do ambiente escolar e se são facilmente percebidas torna-se primordial ao estudo da resiliência infantil. Durante a entrevista abordou-se a percepção das entrevistadas quando uma criança está com algum problema familiar, como a separação dos pais; como a criança demonstra e se queixa desta situação; se há reflexos no ambiente escolar; quais estratégias comumente são utilizadas; por quanto tempo suas reações são vivenciadas; de que forma atenuar possíveis sofrimentos e, principalmente, como se percebe a resiliência infantil.

\section{Análise e discussão de dados}

A abordagem para com os docentes foi iniciada com a explanação do conceito de resiliência e, posteriormente, fez-se a verificação da presença desta nas crianças, diante dos relatos nas entrevistas. Buscou-se primariamente in- 
vestigar, se há de fato uma visibilidade de possíveis dificuldades ou alterações associadas aos problemas de ordem familiar em salas de aula. A professora Y contribui: "a gente percebe por causa do comportamento da criança. [...] talvez até de uma maneira inconsciente, ela quer chamar atenção sobre si de alguma maneira". Percebe-se frequentes alterações em nível comportamental dentre os pequenos: "às vezes ficam agressivos, mais quietos e na aprendizagem podem surgir algumas dificuldades que não apareciam anteriormente" (Professora V).

Especificamente em se tratando do divórcio, Papalia, Olds e Feldman (2006, p. 410) afirmam que, "por mais infeliz que um casamento tenha sido, seu rompimento geralmente representa um choque para uma criança". Dentre diversas manifestações, "tem crianças que se retraem, tem crianças que demonstram atitudes agressivas, depende muito da personalidade da criança, cada uma apresenta, reage de forma diferente" (Professora Y). A adaptação de uma criança ao divórcio, bem como suas respostas a ele, compreende importantes aspectos como "a idade ou a maturidade, o sexo, o temperamento e a adaptação psicológica e social da criança [...]" (PAPALIA; OLDS; FELDMAN, 2006, p. 410). Cada um destes aspectos imprime um modo específico de enfrentamento.

A personalidade de cada criança, composta de comportamentos apreendidos socialmente e de elementos herdados em seu temperamento, molda o comportamento para com o fato, bem como prediz sua resiliência. "A personalidade é encarada com um fator facilitador ou não na adaptação pós-divórcio" (HACK; RAMIRES, 2010, p. 90). A presença da resiliência por parte da criança acometida pelo divórcio de seus pais foi, então, associada a fatores como a sua personalidade.

Outros reflexos apanhados falam da relação divórcio dos pais com o ambiente escolar: "O interesse pelas atividades da sala de aula decai. Como a criança muda de comportamento, reflete na aprendizagem" (Professora Z). A professora Y reforça: "O rendimento escolar dela também pode ser afetado, isso a gente observa que acaba decaindo, até a apresentação de trabalho de escola, as próprias avaliações que a gente faz, na própria organização dos cadernos". Entende-se que há casos em que, para os filhos, o divórcio ocasiona dificuldades escolares, pode-se tornar, até então, um obstáculo à aprendizagem (PILETTI, 2003). Isso posto, o fenômeno da separação dos pais possibilita comprometer o processo ensino-aprendizagem na escola.

Além das modificações no rendimento escolar, as emoções da criança neste período, quanto a seus sentimentos, também podem ficar inquietas. "Crianças em idade escolar são sensíveis às pressões dos pais e conflitos de lealdade; como as crianças mais jovens, podem temer o abandono e a rejeição" (PAPALIA; OLDS; FELDMAN, 2006, p. 410). Foram observados: "Medo, insegurança, eles vem com a fala bem triste, às vezes choram contando pra gente. A questão emocional é bem presente, eles mostram bastante o sentimento deles 
em relação a isso" (Professora X). E falas como: "professora, não me deixa, (Professora Z), foram presenciadas.

As estratégias encontradas nas crianças para lidar com o divórcio de seus pais foram percebidas por meio de seus comportamentos: "[...] usam de agressão, muitas vezes ficam bem manhosas", (Professora V); "isolamento, mentira, fantasias do tipo: 'meu pai vem me buscar hoje' e não é o pai quem vem buscar" (Professora Z); e também na forma de "carência afetiva" (Professora W).

As crianças também se queixam verbalmente acerca do divórcio de seus pais com seus professores. Ressaltam as professoras:

"Elas falam sobre esse assunto e geralmente sabem de tudo, o
motivo, se houve traição ou não, elas escutam tudo! E se quei-
xam: eu queria que a minha mãe aceitasse meu pai de volta"
(Professora Z).

"eles dizem: 'eu não quero que meu pai e minha mãe se separem', eles sempre falam da briga, que eu vou ter que ficar na casa do meu pai ou vou ter que ficar na casa da minha mãe" (Professora X).

A criança, seja positiva ou negativamente, tem suas reações para cada situação da vida. Neste caso, cada entrevistada sugeriu, por meio de suas observações e de sua experiência profissional, formas que amenizariam o sofrimento da criança advindo do divórcio. Algumas delas contam com a conversa com a criança e com a sua família fazendo o uso do diálogo nesses momentos, a exemplo da professora V:

\footnotetext{
"[...] nós, enquanto escola, podemos conversar, no máximo fazer esse diálogo. E chamar os pais, mesmo separados, e tentar conversar, explicar, mas nem sempre conseguimos alcançá-los porque começam botar um contra o outro na nossa frente".
}

Uma estratégia afetiva também pode ser adotada, como cita a professora Z: "Precisa haver muita compreensão, amor, carinho, escutar, acalmar a criança". Para Molon e Santos (2008, p. 5), "Crianças com grandes dificuldades no plano interpessoal familiar buscarão, na maioria das vezes, um olhar afetivo do professor". E, assim, a afetividade encontrada nestes conforta e colabora para o enfrentamento.

Quando o divórcio dos pais foi vivenciado positivamente pelos filhos, comumente percebeu-se a efetiva participação de ambos os genitores na vida dos filhos e uma qualidade no relacionamento entre eles, antes e depois do rompimento conjugal. Manter-se tal relação enriquece a resiliência dos filhos (ASSIS, 2006). 
Há casos que surpreenderam pelo modo sereno de a criança lidar com o rompimento de seus pais:

\begin{abstract}
"Uma das situações que mais me chamou atenção positivamente foi de um menino que tem uma aliança feita das alianças dos pais. Eles explicaram a ele que aquela aliança representa o amor da relação que tiveram: o filho [...] como os pais são bem resolvidos emocionalmente, aceitaram numa boa. Esse menino não apresenta problemas emocionais" (Professora Z).
\end{abstract}

A criança consegue se tornar mais forte quando encontra um cuidado, uma atenção e um apoio em suas vivências (WALSH, 2005); apoio este que pode ser encontrado na figura de um de seus genitores, um adulto ou outro cuidador que a cerca.

A família acaba por assumir grande importância para a criança no divórcio dos pais. À medida que, de forma clara e compreensível a decisão do divórcio é comunicada aos filhos, menos fantasias eles criam acerca desta situação e mais chances têm de elaborar o ocorrido, saudáveis emocionalmente. "A forma como pais e familiares transmitem às crianças e adolescentes suas emoções serve para acalmar ou deixar elas mais aflitas" (ASSIS, 2006, p. 14).

Grunspun (2006, p. 21) ressalta que "a criança resiliente consegue resistir à adversidade, lutar com as incertezas e se recuperar com maior sucesso de eventos ou episódios traumáticos". Isto não significa que, para todo e qualquer divórcio dos pais, haverá filhos comprometidos. Há crianças resilientes, enriquecidas por uma combinação de fatores ao longo de suas criações, que passam por situações estressoras de modo a não perderem seu equilíbrio psíquico e não serem prejudicadas em demasia em seu desenvolvimento.

Apesar de haver casos em que as crianças reagem positivamente à situação proposta, por devidas razões, não é a postura encontrada em sua maioria. " $O$ que eu mais lembro assim são de crianças que não tiveram uma superação assim, uma superação positiva" (Professora X). Conforme Papalia, Olds e Feldman (2006, p. 411), "meninos que crescem em uma atmosfera de ódio e de discórdia entre os pais tendem a se tornar agressivos, e as meninas tendem a se tornar retraídas e ansiosas". Neste ínterim, o conflito conjugal é exposto aos filhos, traz para estes reações emocionais e comportamentais em resposta a essas discussões familiares. De acordo com este depoimento da professora Z:

\footnotetext{
"Um dos casos mais dificeis foi de um menino, de 10 anos, que era muito agressivo, inclusive comigo. Já com o professor, homem, ele não tinha nenhuma agressividade, tinha um bom comportamento [...] ele tinha problemas com a mãe, e com o pai possuía um melhor relacionamento. Para ele, a mãe fazia o papel 'chato', que cobrava o estudo, comer na hora certa, ir à igreja, dormir cedo [...]. O pai era o amigão, dava presentes caros [...] comia só o que queria, dormia tarde, podia jogar
} 
videogame muitas horas [...]. Um exemplo foi de o menino ser suspenso da catequese por um tempo, pois riscou todo o banco da igreja”.

Quanto ao tempo que as crianças demoravam para conseguir voltar ao seu ritmo usual na escola depois do divórcio pais, não se obteve respostas concretas. Partiu-se do pressuposto de que, em geral, cada caso é um caso. "Vai de cada relação, vai de cada criança. É bem relativo, mensurar, não tem como" (Professora V). Quanto à esta indagação, novas considerações foram realizadas, à medida que se passou a conviver mais com este fenômeno: "percebo que eles têm hoje, pela frequência das separações, as referências dos amigos. Muitos deles são filhos de pais separados e eles escutam que tem duas casas, duas familias, então parece que isso os ajuda a lidarem melhor com isso" (Professora Z).

A diminuição dos conflitos conjugais também parece ajudar. "Às vezes, o divórcio pode melhorar a situação de uma criança, reduzindo a quantidade de conflito numa família [...]". (PAPALIA; OLDS; FELDMAN, 2006, p. 411). Logo, o afastamento dos cônjuges possibilita uma trégua nas discussões familiares que muito atingem a criança pela falta de clareza diante do fato.

Intervir na resiliência infantil, e contribuir para que haja um desenvolvimento dessa capacidade de lidar com as situações estressoras e até mesmo traumáticas, de forma que atenue tais efeitos do divórcio dos pais já mostrados anteriormente, envolve fatores promocionais e protetores contra os de risco. "A resiliência é a interseção entre alto risco versus recursos excepcionais de proteção" (GRUNSPUN, 2006, p. 34).

Visando à sua promoção, dentro do cenário do divórcio, as professoras descreveram possíveis caminhos:

"Diálogos bem abertos entre escola e pais, observação, projetos educacionais envolvendo uma educação emocional, trabalhando com textos e historinhas sobre valores para levar as crianças refletirem"( Professora Z).

\footnotetext{
"A professora com a criança, é se mostrando disponivel pra acolher a criança no sentimento dela, a forma como ela tá compreendendo tudo o que tá acontecendo. A escola, convidar a mãe para uma reunião, se mostrar também disponível, que tá atenta, e compreende que é dificil [...]" (Professora W).
}

A escola e os professores tornam-se agentes promotores de resiliência quando conseguem desenvolver em sua prática pedagógica, de forma criativa e persistente, importantes valores humanos, uma educação emocional, um fortalecimento das relações interpessoais e dos fatores de proteção. "[...] depois 
da família, a escola é o meio fundamental e essencial para que as crianças, na sala de aula, adquiram as competências necessárias para ter sucesso na vida, por meio da superação das adversidades" (FAJARDO;MINAYO; MOREIRA, 2010, p. 766).

Nela, a resiliência pode ser inserida aos projetos e aos conteúdos educacionais, conforme coloca esta professora:

\begin{abstract}
“[...] a gente trabalha o conteúdo família [...] procura tá mostrando os tipos de famílias, tem familias só de pai e filho, familias de mãe e filho, a gente fala as várias famílias que tem hoje, que também é uma ajuda pra essa superação, que isso não exatamente seja normal, mais que isso acontece e que tudo bem" (Professora X).
\end{abstract}

Quando a escola reconhece que situações familiares podem intervir no processo de aprendizagem da criança, que existem diferentes tipos de famílias e características singulares entre seus alunos, previne, e até mesmo evita, os famosos obstáculos à aprendizagem (PILETTI, 2003), pois, considerando as diferenças, alcança a todos e cumpre seu papel sócio-educacional.

Ainda que o ambiente escolar seja cenário familiar da criança e que significativamente colabore para o seu desenvolvimento físico, cognitivo e psicossocial, em determinados casos de divórcio, a escola reconhece que há necessidade do cuidado de outros profissionais, como psicólogos, na lida deste fenômeno. "A partir do momento que percebemos que é um problema de relacionamento, emocional, fazemos um encaminhamento. Também realizamos orientações e geralmente trabalhamos com uma equipe" (Professora V).

Os encaminhamentos realizados pela escola demonstram o reconhecimento do trabalho interdisciplinar. Para Martínez (2003, p. 108), "para ser desenvolvida a função educativa na escola na sua complexidade e com maiores níveis de eficiência, torna-se necessária à participação de profissionais diversos", cada qual com sua específica contribuição, enriquecem os olhares para o fenômeno em questão. A maioria das entrevistadas, quando necessário, faz os devidos encaminhamentos.

\section{Considerações finais}

A partir da pesquisa, pôde-se perceber que, segundo as professoras, há resiliência infantil, que há reações emocionalmente saudáveis das crianças no divórcio dos pais, na proporção que estes instituem e cultivam consideráveis valores e aspectos na vida de seus filhos e, a combinação destes, colabora para uma capacidade resiliente, para um enfrentamento da situação estressora.

A partir dos dados analisados, aliados ao referencial teórico, observou-se que a manutenção do relacionamento entre pais e filhos após a dissolução 
familiar, o acolhimento dos genitores e o livre acesso a eles, de modo a passar com os pais o tempo necessário para suprir a carência afetiva dos filhos, são formas de dar continuidade aos laços afetivos entre a família e, portanto, fortalecer sua resiliência. Atenta-se, também, para uma comunicação esclarecedora sobre o divórcio aos filhos, sobre decisão e sua real situação, a fim de que não sejam nutridas fantasias, culpa e demais sintomas.

Salienta-se que, ao lidar com o divórcio dos pais, as estratégias de enfrentamento encontradas pelas crianças foram o uso de agressividade, queda no rendimento escolar, carência afetiva. Constatou-se que a família, bem como a escola, são poderosos promotores de resiliência quando desenvolvem características e condições que formam e potencializam os fatores de proteção para as adversidades da vida. A resiliência infantil no divórcio dos pais pode ser promovida pelos próprios pais e pela escola, para que os filhos passem por este momento de forma menos dolorosa, amparados emocionalmente e obtendo crescimento, na proporção que seus recursos internos e externos se articulam, gerando novas competências.

Por fim, evidencia-se que explorar a resiliência assemelha-se a ampliar as diversas formas de enfrentamento, de movimentação pró-ativa de uma criança, de um indivíduo frente a seus traumas, seus conflitos e suas adversidades cotidianas, para poder contemplar suas alegrias, mas também suas dificuldades, sabendo extrair proveito delas, enquanto amadurecimento e crescimento pessoal, no que diz respeito às crianças e sua relação com o divórcio dos pais.

\section{Referências Bibliográficas:}

APPOLINÁRIO, Fábio. Metodologia da ciência: filosofia e prática da pesquisa. São Paulo: Thomson, 2006. 209 p.

ASSIS, Simone Gonçalves. De Fundação Oswaldo Cruz. Por que é importante ajudar os filhos a "dar a volta" por cima? Conversando com pais de crianças e adolescentes sobre as dificuldades da vida. Rio de Janeiro: FIOCRUZ, 2006. 44 p.

ÁVILA, Eliedite Mattos. Mediação familiar: formação de base. Florianópolis: Serviço de Mediação Familiar, 2004. 117 p.

BRANDÃO, Eduardo Ponte. A interlocução com o Direito a luz das praticas psicológicas em Varas de Famílias. In: GONÇALVES Hebe Signorini; BRANDÃO, Eduardo Ponte. Psicologia Jurídica no Brasil. 2. ed Rio de Janeiro: NAU, 2008, p.51-97.

CARTER, Betty; MCGOLDRICK, Monica. As mudanças no Ciclo de Vida Familiar: Uma Estrutura para a Terapia Familiar. In: CARTER, Betty; MCGOLDRICK, Monica. As Mudanças no Ciclo de Vida Familiar: uma estrutura para a terapia familiar. 2. ed. Porto Alegre: Artmed, 2001, p.7-29.

FAJARDO, Indinalva Nepomuceno; MINAYO, Maria Cecilia de Souza; MOREIRA, Carlos Otávio Fiúza. Educação escolar e resiliência: política de educação e a prática docente em meios adversos. Ensaio: aval. pol. públ. Educ., Rio de Janeiro, v. 18, n. 69, p. 761-774, out./dez. 2010. 
GIL, Antonio Carlos. Como elaborar projetos de pesquisa. 4.ed São Paulo: Atlas, 2002. 175 p.

GRUNSPUN, Haim. Criando filhos vitoriosos: quando e como promover a resiliência. São Paulo: Ed. Atheneu, 2006. 212 p.

HACK, Soraya Maria Pandolfi Koch; RAMIRES, Vera Regina Rohnelt. Adolescência e Divórcio Parental: Continuidades e rupturas dos relacionamentos. Psicologia Clínica, Rio de Janeiro, v. 22, n. 1, p. $85-97,2010$.

INSTITUTO BRASILEIRO DE GEOGRAFIA E ESTATÍSTICA (IBGE). Censo demográfico 2010. Características gerais da população: resultados da amostra. Rio de Janeiro: Instituto Brasileiro de Geografia e Estatística, 2010.

JUNQUEIRA, Maria de Fátima Pinheiro da Silva; DESLANDES, Suely Ferreira Deslandes. Resiliência e maus-tratos à criança. Cad. Saúde Pública, Rio de Janeiro, v.19, n.1, p. 227-235, jan-fev, 2003.

MARTÍNEZ, Albertina Mitjáns. O Psicólogo na Construção da Proposta Pedagógica da Escola: Áreas de Atuação e Desafios para a Formação. In: ALMEIDA, Sandra Francesca Conte de. Psicologia Escolar: Ética e competências na formação e atuação profissional. São Paulo: Editora Alínea, 2003, p.105-124.

MCGOLDRICK, Monica. A União das Famílias Através do Casamento: O Novo Casal. In: CARTER, Betty; MCGOLDRICK, Monica. As mudanças no ciclo de vida familiar: uma estrutura para a terapia familiar. 2.ed. Porto Alegre: Artmed, 2001, p.184-205.

MOLON, Karina Silva; SANTOS, Bettina Steren dos. O papel do professor para o desenvolvimento afetivo-emocional do aluno. In: MOSTRA DE PESQUISA DA PÓS-GRADUAÇÃO, 3, PUCRS, Porto Alegre, 2008. Disponível em: http://www.pucrs.br/edipucrs/online/IIImostra/ Educacao/62821\%20-\%20KARINA\%20SILVA\%20MOLON.pdf. Acesso em: 02 mai. 2013.

OLIVEIRA, Marileide A. de, REIS, Verônica Lima dos, ZANELATO, Luciana Silva; NEME, Carmem Maria Bueno. Resiliência: Análise das Publicações no Período de 2000 a 2006. Psicologia, Ciência e Profissão, [S.1.], v. 28, n.4, p. 754-767, 2008.

PAPALIA, Diane E; OLDS, Sally Wendkos; FELDMAN, Ruth Duskin. Desenvolvimento Humano. 8. ed. Porto Alegre: Artmed, 2006. 888 p.

PECK Judith Stern; MANOCHERIAN, Jennifer. O Divórcio nas Mudanças do Ciclo de Vida Familiar. In: CARTER, Betty; MCGOLDRICK, Monica. As mudanças no ciclo de vida familiar: uma estrutura para a terapia familiar. 2.ed. Porto Alegre: Artmed, 2001, p.291-320.

PILETTI, Nelson. Psicologia educacional. 17 ed. São Paulo: Ática, 2003. 336 p.

WALSH, Froma. Fortalecendo a Resiliência Familiar. São Paulo: Roca, 2005. 314 p.

YUNES, Maria Angela Mattar. A Questão Triplamente Controvertida da Resiliência em Famílias de Baixa Renda. São Paulo, 2001, 168 fl. Tese (Doutorado em Psicologia da Educação), Pontifícia Universidade Católica de São Paulo, São Paulo, 2001.

YUNES, Maria Angela Mattar. Psicologia positiva e resiliência: o foco no indivíduo e na família. Psicologia em Estudo, Maringá, v. 8 (num.esp.), p. 75-84, 2003. 
Submissão em: 28/06/2013

Aceite em: 20/03/2014

Camila Comin Pizzolo Gaidzinski é psicóloga, formada pela Universidade do Extremo Sul Catarinense - UNESC. Em formação pelo Centro de Estudos Luís Guedes - CELG, na Introdução à Psicoterapia de Orientação Analítica. Endereço: R. Eng. Fiúza da Rocha, 500. Centro. Criciúma/SC, Brasil. CEP 88801-400. E-mail: milapizzolo@hotmail.com

Denise Nuernberg é coordenadora Adjunta e Professora do Curso Psicologia da Universidade do Extremo Sul Catarinense; Coordenadora do Programa de Orientação Profissional - POP; Assessora do Estágio em Psicologia Clínica - Estágio D; Psicóloga Clínica - Formação em Psicoterapia de Orientação Analítica e Psicóloga Escolar E-mail: deniseunesc@,gmail.com

Patrícia Maria Spido é Psicóloga Clínica, com formação em Terapia Relacional Sistêmica e em Psicologia Corporal. É presidente da CERES - Associação Criciumense de Apoio à Saúde Mental. E-mail: patriciaspido@yahoo.com.br

Rosa Nadir Teixeira Jerônimo é Professora nos Cursos de Psicologia e Arquitetura, Extensionista do Projeto Coleta Seletiva Solidária, Pesquisadora do Grupo de Pesquisa Trabalho, Organizações, Ambiente e Políticas Públicas: Estudos Interdisciplinares na linha de pesquisa: Psicologia ambiental, espaços de vida e saúde mental da

Universidade do Extremo Sul Catarinense - UNESC. E-mail: rnj@unesc.net 